\title{
PENGARUH TINGKAT SUKU BUNGA DEPOSITO TERHADAP JUMLAH DANA DEPOSITO BERJANGKA PADA PT. BANK TABUNGAN PENSIUNAN NASIONAL Tbk.
}

\author{
ALFIANI AP.* AHADI RERUNG, SE., M. Si.** AGUS SUNARYO, SE., M.Si. ** \\ *Mahasiswa Prodi Keuangan Perbankan, STIE Port Numbay Jayapura \\ **Dosen Prodi Keuangan Perbankan, STIE Port Numbay Jayapura
}

\begin{abstract}
This study was conducted to analyze the effect of interest rates on the amount of time deposit funds at PT. BTPN (tbk). This study aims to determine whether there is an effect of deposit interest rates on the amount of time deposit funds at PT. BTPN (tbk). In this study, the sample taken was data on receipt of deposit funds in 2015 to 2019. This study used data collection techniques through library techniques and data collection through field studies. The analytical method used is simple linear regression using SPSS version 20.00 for Windows. Based on the results of the research that has been done, it shows that the deposit rate variable has no effect on the amount of time deposit funds.
\end{abstract}

Keywords: deposit interest rate, amount of time deposit funds.

Abstrak: Penelitian ini dilakukan untuk menganalisis pengaruh tingkat suku bunga terhadap jumlah dana deposito Berjangka pada PT. BTPN (tbk). Penelitian ini bertujuan untuk mengetahui apakah ada pengaruh suku bunga deposito terhadap jumlah dana deposito berjangka pada PT. BTPN (tbk). Dalam penelitian ini sampel yang diambil adalah data penerimaan dana deposito pada tahun 2015 sampai 2019. Penelitian ini menggunakan teknik pengumpulan data melalui teknik kepustakaan dan pengumpulan data melalui studi lapangan. Metode analisis yang di gunakan adalah regresi linear sederhana dengan menggunakan alat bantu program SPSS versi 20.00 for Windows. Berdasarkan hasil penelitian yang telah dilakukan, menunjukkan bahwa variabel tingkat suku bunga deposito tidak berpengaruh terhadap jumlah dana deposito berjangka.

Kata kunci : tingkat suku bunga deposito, jumlah dana deposito berjangka.

\section{PENDAHULUAN}

Dunia perbankan sebagai lembaga keuangan akan bersaing untuk mendapatkan kepercayaan dari masyarakat agar dapat membantu kelancaran aktivitas dalam perbankan. Pada dasarnya inti dari semua kebijaksanaan yang ada adalah untuk memberikan kebebasan kepada dunia perbankan dalam usahanya menghimpun dana dari masyarakat dan kemudian menyalurkannya kembali kepada masyarakat atau perusahaan untuk membantu dan melancarkan aktivitas dalam kehidupan masyarakat tertentu. Dengan bertambahnya nilai suatu dana merupakan suatu perkembangan yang diinginkan oleh para pemilik dana baik dalam jangka pendek maupun untuk masa yang akan datang.

Oleh karena itu, bank dituntut untuk lebih memaksimalkan kinerjanya dalam berbagai hal terutama dalam hal memperoleh laba karena pada umumnya bank didirikan dengan tujuan untuk memperoleh laba atau keuntungan yang semaksimal mungkin demi menjamin kelangsungan hidup bank tersebut agar tetap bertahan sampai masa yang akan datang. Untuk mencapai tujuan tersebut, sangat diperlukan adanya kerjasama yang baik antara manajer bersama para karyawannya dalam memanfaatkan dan mengelolah sumber-sumber dana yang ada dalam bank tersebut secara efisien dan efektif. Bagi bank dapat menjadi tolak ukur terhadap kerja yang telah bank lakukan sehingga dapat mencegah hal yang dapat menghambat kinerja bank itu sendiri.

Kebijaksanaan suku bunga akan mempengaruhi tinggi rendahnya suku bunga yang ditetapkan sehingga setiap bank berusaha sedemikian rupa agar suku bunga tidak memberatkan bagi usaha pembangunan dan juga tidak memberatkan para nasabah atau para pengusaha. Selain itu kebijaksanaan suku bunga harus mencerminkan langkanya modal yang tersedia dalam perekonomian dan keseluruhan biaya penyaluran modal dari penabung kepada peminjam.

Kegiatam umum bank sebagai intermediary financial pada dasarnya adalah memobilisasi dana dari masyarakat untuk selanjutnya disalurkan kepada perorangan atau lembaga yang membutuhkan dana dalam bentuk pinjaman atau kredit untuk keperluan investasi. Individu atau lembaga yang memiliki kelebihan dana memerlukan institusi yang dapat mengelola kelebihan dananya tersebut secara efektif dan menguntungkan. Mereka dapat mempercayakan 
pengelolaan dana tersebut kepada bank dalam bentuk tabungan, deposito maupun giro. Nasabah lebih memilih menginvestasikan kelebihan dananya pada tempat yang memberikan keuntungan yang besar di sertai degan rasa aman.

Hal ini yang menjadi alasan bagi penulis untuk melakukan penelitian mengenai tingkat suku bunga deposito dan jumlah deposito pada PT. Bank Tabungan Pensiun Nasional. Nasabah memilih dan menggunakan produk deposito, karena pada dasarnya nasabah menginginkan pendapatan bunga yang besar dari dana yang didepositokan pada bank tersebut.

\section{Rumusan Masalah}

Berdasarkan uraian pada latar belakang di atas, maka rumusan masalah yang akan dibahas dalam penelitian ini adalah: Apakah ada pengaruh Tingkat Suku Bunga Deposito Terhadap Jumlah dana deposito berjangka pada PT. Bank Tabungan Pensiunan Nasional Tbk, tahun 2015 sampai 2019?

\section{LANDASAN TEORI}

\section{Pengertian Bank}

Secara umum pengertian bank adalah suatu lembaga keuangan yang menghimpun dana dari masyarakat berupa giro, tabungan, deposito dan pemberian jasa bank serta menyalurkan kembali dana tersebut kepada masyarakat atau pihak yang membutuhkan dalam bentuk kredit.

Menurut Kasmir (2012:12) Bank adalah lembaga keuangan yang kegiatan utamanya menghimpun dana dari masyarakat dan menyalurkan kembali dana tersebut kepada masyarakat serta memberikan jasajasa bank lainnya. Sedangkan Menurut UU No.10 Tahun 1998 tanggal 10 November 1998 tentang Perbankan, yang di maksud dengan bank adalah badan usaha yang menghimpun dana dari masyarakat dalam bentuk simpanan dan menyalurkannya kepada masyarakat dalam bentuk kredit dan atau bentuk lainnya dalam rangka meningkatkan taraf hidup rakyat banyak. Kegiatan perbankan yang paling pokok adalah membeli uang dengan cara menghimpun dana dari masyarakat luas, kemudian menjual uang yang berhasil dihimpun dengan cara menyalurkan kembali kepada masyarakat melalui pemberian pinjaman kredit.

\section{Pengertian Deposito}

Simpanan deposito Menurut Kasmir (2016:74) merupakan simpanan jenis ketiga yang di keluarkan oleh bank. Berbeda dengan simpanan giro dan tabugan, di mana simpanan deposito mengandung unsur jangka waktu (jatuh tempo) lebih panjang dan tidak dapat ditarik setiap saat atau setiap hari. UdangUndang No. 10 Tahun 1998 yang dimaksud dengan deposito adalah simpanan yang penarikannya hanya dapat dilakukan pada waktu tertentu berdasarkan perjanjian nasabah penyimpan dengan bank. Artinya jika nasabah deposan menyimpan uangnya untuk jangka waktu tiga bulan, maka uang tersebut baru dapat dicairkan setelah jangka waktu tersebut berakhir dan sering disebut tanggal jatuh tempo.

Menurut Thomas Suyanto, (2014) Deposito adalah tabungan di bank dimana penarikannya hanya biasa dilakukan dalam jangka waktu tertentu sesuai dengan pejanjian antara nasabah dengan bank yang bersangkutan. Sedang menurut Muhammad Hassanudin dan Habib Nazir (2004) Deposito adalah simpanan berjangka dari pihak ketiga pada bank dimana penarikannya hanya bisa dilakukan sesuai dengan jangka waktu yang telah ditentukan sesuai perjanjian antara pihak ketiga dan pihak bank.

\section{Fungsi Deposito}

Menurut Kasmir (2008:65) fungsi deposito mempunyai peranaan penting karena sumber modal dari bank, sumber dana dari masyarakat yang nantinya oleh bank akan dimanfaatkan kembali dan disaluran dalam bentuk-bentuk kredit ataupun produk-produk lain dari bank. Dengan demikian deposito merupakan suatu cara untuk mengatur kehidupan perekonomian.

Adapun fungsi deposito ditinjau dari segi kepentingan bank itu sendiri mempunyai tiga aspek, yaitu:

a) Dari segi bank

Merupakan salah satu bentuk usaha bank untuk menghimpun dana dari masyarakat atau badan hukum, sebagai penambah modal guna menujang usaha perbankan khususnya dibidang perkreditan dengan sumber memberikan suatu rangsangan berupa suku bunga deposito.

b) Dari segi deposan

Dengan menghimpun dana akan memperolah bunga yang cukup tinggi dibandingkan dengan simpanan lain, memperoleh jaminan kredit, selain itu juga dapat mengelola keuangan secara lebih terencana sesuai dengan kebutuhan jangka waktu deposito.

c) Dari segi perkembangan Ekonomi

Saat dana masyarakat terhimpun oleh bank dan disalurkan dalam bentuk kredit, digunakan secara maksimal guna keperluan produktif, maka dapat meningkatkan pendapatan nasianal dan kesejahteraan masyarakat. 


\section{Bunga Deposito}

Menurut Kasmir (2008:54) Bunga deposito adalah selalu lebih besar dari bunga tabungan sehingga otomatis akan berkembang lebih cepat. Inilah biasanya yang menjadi daya tarik utama deposito, sehingga deposito lebih cocok dijadikan sarana investasi dibandingkan tabungan tambahkan.

Tingkat suku bunga menurut Boediono (2014:76) adalah harga dari penggunaan dana investasi (loanable funds). Tingkat suku bunga merupakan salah satu indicator dalam menentukan apakah seseorang akan melakukan investasi atau menabung. Pengertian suku bunga menurut Sunariyah (2013:80) adalah harga dari pinjaman. Suku bunga dinyatakan sebagai peresentase uang pokok per unit waktu. Bunga merupakan suatu ukuran sumber daya yang digunakan oleh debitur yang harus dibayarkan kepada kreditur. Selain suku bunga internasional, tingkat diskonto suku bunga Indonesia (SBI) juga merupakan factor penting dalam penentuan suku bunga di Indonesia. Tingkat suku bunga atau interest rate merupakan rasio pengambilan sejumlah investasi sebagai bentuk imbalan yang diberikan kepada investor.

\section{METODE PENELITIAN}

\section{Jenis Data dan Sumber Data}

a. Data Primer

Data primer, yaitu data yang diperoleh melalui pertanyaan yang langsung diajukan kepada objek penelitian yaitu: PT. Bank Tabungan Pensiunan Nasional dalam hal ini langsung kepada pemimpin PT. Bank Tabungan Pensiunan Nasional Tbk.

b. Data Sekunder

Data sekunder diperoleh dengan jalan menganalisa dokumen, referensi yang ada kaitannya dengan pokok permasalahan dalam penelitian ini.

\section{Teknik Pengumpulan Data}

Dalam penelitian ini, teknik pengumpulan data dilakukan dengan melalui dua metode, yaitu:

1) Studi Keperpustakaan (Libray Research) yaitu dengan mengumpulkan data penunjang lewat perpustakaan sebagai materi yang berkaitan dengan penelitian sebagai bahan acun dalam penulis.

2) Obvervasi

Obvervasi bertujuan untuk mengamati subjek dan objek penelitian, sehingga penelitian dapat memahami kondisi yang sebenarnya. Pengamatan bersifat nonpartisipatif, yaitu penelitian berada diluar sistem yang diamati.

\section{Hipotesis}

Berdasarkan permasalahan dan landasan analisa teori di atas dapat disusun suatu hipotesa yang merupakan jawaban sementara dan permasalahan penelitian yang masih harus dibuktikan secara emperis yaitu sebagai berikut:

"Diduga tingkat suku bunga deposito berpengaruh signifikan dan positif terhadap jumlah dana deposito berjangka pada PT. Bank Tabungan Pensiunan Nasional Tbk"

\section{Metode Analisis Data}

Tujuan analisis di dalam penelitian adalah memfokuskan substansi masalah yaitu mengenai pengaruh tingkat suku bunga deposito terhadap jumlah dana deposito berjangka. Proses analisis data merupakan usaha jawaban atas pernyataan dan pertanyaan yang terdapat dalam proses penelitian. Yaitu alat analisi data yang menggunakan rumusrumus tertentu yang sesuai dengan topik permasalahan yang diteliti. Alat yang digunakan untuk memecahkan masalah yang diteliti yaitu melalui alat analisis regresi sederhana, metode ini digunakan untuk menganalisis pengaruh tingkat suku bunga deposito dan jumlah dana deposito berjangka pada PT. Bank Tabungan Pensiunan Nasional Tbk.

Perhitungan statistik dan pengujian hipotesis dengan analisis regresi sederhana (regresi linear) dalam penelitian ini dilakukan dengan progam computer spss versi 20.

\section{Regresi Sederhana (regresi linear)}

Menurut Sugiyono (2014:270) Regresi sederhana didasarkan pada hubungan fungsional ataupun kausal satu variable independen dengan satu variable dependen. Rumus regresi sederhana, yaitu:

$$
\begin{aligned}
& \mathrm{Y}=\mathrm{a}+\mathrm{bX}+\mathrm{e} \\
& \mathrm{b}=\frac{n \Sigma X Y-\Sigma X \Sigma Y}{n \Sigma X^{2}-(\Sigma X)^{2}} \\
& \mathrm{a}=\frac{\Sigma Y-b_{\Sigma} y}{n}
\end{aligned}
$$

Dimana

Y : Jumlah deposito.

$\mathrm{X} \quad$ : Tingkat suku bunga.

$\mathrm{n} \quad$ : Jumlah data yang dianalisis.

a : Nilai konstan.

b : Koefisien regresi

\section{Korelasi Product Moment}

Menurut Sugiyono (2010:183) korelasi product moment merupakan salah satu alat analisis dalam statistik yang digunakan untuk mengetahui kekuatan hubungan antara 
korelasi kedua variabel dimana variabel lainnya yang dianggap berpengaruh di kendalikan atau di buat.

Rumus korelasi product moment yaitu:

$$
\operatorname{rxy}=\frac{n \Sigma x y-(\Sigma x)(\Sigma y)}{\left.\sqrt{\left(n \Sigma x^{2}\right.}-(\Sigma x)^{2}\right)\left(n \Sigma y^{2}-(\Sigma y)^{2}\right)}
$$

Keterangan:

rxy $\quad=$ koefisien korelasi

$\sum \mathrm{x} \quad=$ jumlah nilai variabel $(\mathrm{x})$

$\sum \mathrm{y}=$ jumlah nilai variabel $(\mathrm{y})$

$\sum x^{2} \quad=$ jumlah nilai kuadrat variabel $(\mathrm{x})$

$\sum Y^{2} \quad=$ jumlah nilai kuadrat variabel $(\mathrm{y})$

$\sum x y=$ jumlah nilai kuadrat variabel $(\mathrm{xy})$

$\mathrm{n} \quad=$ jumlah sampel

Besar kecilnya sumbangan nilai variabel $\mathrm{X}$ terhadap Y dapat ditentukan dengan rumus koefisien determinasi sebagai berikut:

di mana:

$$
\mathrm{R}=r^{2} \times 100 \%
$$

$\mathrm{R}=$ nilai koefisien determinasi

$\mathrm{r}=$ nilai koefisien korelasi

\section{Uji t}

Menurut Sugiyono (2014-250) Uji t adalah untuk mengetahui Apakah variabel bebas secara individual atau mempunyai pengaruh terhadap variabel terkait dengan asumsi variable yang lain.

Untuk melakukan pengujian $t$ maka dapat digunakan rumus sebagai berikut.

$$
\mathrm{t}=\frac{r \sqrt{n-2}}{\sqrt{1-r^{2}}}
$$

Keterangan

t : Distribusi t

$$
\begin{array}{ll}
\mathrm{r} & : \text { Koefisien kolerasi parsial } \\
r^{2} & : \text { Koefisien determinasi } \\
\mathrm{n} & : \text { Jumlah data }
\end{array}
$$

\section{HASIL ANALISIS}

Berdasarkan pada tujuan penelitian ini sebagaimana telah dikemukakan sebelumnya maka yang pertama akan dianalisis adalah untuk mengetahui pengaruh tingkat suku bunga deposito terhadap jumlah dana deposito berjangka pada PT. Bank Tabungan Pensiunan Nasional (Persero) Tbk. Analisis statistik yang digunakan yaitu model analisis regresi linear sederhana. Untuk memudahkan perhitungan model analisis tersebut digunakan program SPSS 20 dengan pendekatan/prosedur full model Regression.

Selanjutnya untuk membuktikan hipotesis yang diajukan dalam penulisan ini maka dalam melakukan pengujian empris penulis menggunakan metode regresi linier sederhana. Regresi sederhana didasarkan pada hubungan fungsional ataupun kausal satu variabel independen dengan satu variabel dependen. Adapun variabel yang digunakan dalam perhitungan ini yaitu tingkat suku bunga deposito yang merupakan variabel independen, dan jumlah dana deposito yang merupakan variabel dependen. Seluruh data yang digunakan dalam penelitian merupakan data tahun 2015 sampai 2019.

Setelah dilakukan pengujian dengan menggunakan program computer SPSS 20, maka hasil dari data di atas yang dimasukan ke dalam model persamaan Regresi linear sederhana sebagai berikut:

Tabel 1. Variabel Penelitian

Variables Entered/Removed ${ }^{\mathrm{a}}$

\begin{tabular}{|l|l|l|l|}
\hline Model & Variables Entered & \multicolumn{1}{|l|}{$\begin{array}{l}\text { Variables } \\
\text { Removed }\end{array}$} & Method \\
\hline 1 & SukuBunga $^{\mathrm{b}}$ & & Enter \\
\hline
\end{tabular}

a. Dependent Variable: JlmDeposito

b. All requested variables entered.

Sumber: data diolah 2020

Tabel Variabel Entered/Removed di atas menjelaskan tentang variabel yang dimasukan atau dibuang dan metode yang digunakan. Dalam hal ini variable yang dimasukan adalah variabel nilai Suku Bunga sebagai predictor dan metode yang digunakan adalah metode enter. Tabel di atas menunjukan variabel yang diproses, suku bunga deposito menjadi variabel independen dan jumlah dana deposito menjadi variabel dependen.

\section{Analisis Korelasi}

Dari hasil analisis regresi di atas dapat dilihat bahwa variabel tingkat suku bunga deposito merupakan variabel yang mempengaruhi jumlah 
deposito berjangka. Tabel di bawah ini juga menjelaskan hubungan variabel.

Tabel 2. Hasil Analisis Korelasi

Model Summary

\begin{tabular}{|c|c|r|r|r|r|r|r|r|r|}
\hline \multirow{2}{*}{ Model } & \multirow{2}{*}{$\mathrm{R}$} & \multirow{2}{*}{$\mathrm{R}$ Square } & \multirow{2}{*}{$\begin{array}{c}\text { Adjusted } \mathrm{R} \\
\text { Square }\end{array}$} & \multirow{2}{*}{$\begin{array}{l}\text { Std. Error of } \\
\text { the Estimate }\end{array}$} & \multicolumn{5}{|c|}{ Change Statistics } \\
\cline { 5 - 10 } & & & $\begin{array}{l}\text { R Square } \\
\text { Change }\end{array}$ & F Change & df1 & df2 & $\begin{array}{c}\text { Sig. F } \\
\text { Change }\end{array}$ \\
\hline 1 & $.013^{\mathrm{a}}$ & .000 & -.055 & 2473003.511 & .000 & .003 & 1 & 18 & .956 \\
\hline
\end{tabular}

a. Predictors: (Constant), SukuBunga

Sumber: data diolah 2020

Berdasarkan table 2. di atas, hasil regresi didapatkan nilai $\mathrm{R}$ sebesar 0,013 yang berarti bawah tingkat suku bunga deposito memiliki korelasi yang sangat rendah terhadap jumlah deposito berjangka yaitu hanya sebesar 1,3\%, ini dilihat berdasarkan tabel interprestasi koefisien korelasi. Tabel 2. di atas memperhatikan nilai koefisien determinasi (R-Square) yang digunakan untuk mengetahui persentase pengaruh variabel independen terhadap variabel dependen sebesar 0,000. Hal ini berarti tingkat suku bunga deposito tidak berkonstribusi terhadap jumlah deposito berjangka. Pengaruh tingkat suku bunga deposito terhadap jumlah dana deposito sangat rendah, hal ini dilihat berdasarkan tabel interperetasi koefisien korelasi.

\section{Nilai t hitung dan Signifikansi}

Uji t dilakukan untuk mengetahui pengaruh variabel independen (Tingkat suku bunga) terhadap variabel dependen (Jumlah dana deposito). Hasil uji analisis regresi coefficients dengan menggunakan SPSS versi 20 terlihat di bawah ini:

Tabel 3. Hasil Perhitungan Regresi Sederhana

\section{Coefficients $^{\mathbf{a}}$}

\begin{tabular}{|c|c|c|c|c|c|c|}
\hline & \multirow{2}{*}{ Model } & \multicolumn{2}{|c|}{ Unstandardized Coefficients } & \multirow{2}{*}{$\begin{array}{c}\begin{array}{c}\text { Standardized } \\
\text { Coefficients }\end{array} \\
\text { Beta }\end{array}$} & \multirow{2}{*}{$\mathrm{t}$} & \multirow{2}{*}{ Sig. } \\
\hline & & B & Std. Error & & & \\
\hline \multirow{2}{*}{1} & (Constant) & 14607827.130 & 3974323.607 & & 3.676 & .002 \\
\hline & SukuBunga & 2834222.996 & 50980119.570 & .013 & .056 & .956 \\
\hline
\end{tabular}

a. Dependent Variable: JlmDeposito

Sumber : Hasil Olahan SPSS 20 
Untuk mengetahui model di atas layak digunakan atau tidak, hal ini dapat diketahui melalui tingkat signifikansi variabel bebas terhadap variabel terkait baik secara individual maupun secara keseluruhan, maka digunakan statistik uji t.

Untuk membuktikan apakah ada pengaruh antara tingkat suku bunga deposito berjangka terhadap jumlah dana deposito berjangka 3 bulan pada PT. Bank Tabungan Pensiunan Negara, maka dapat di uji-t sebagai berikut :

1) $\mathrm{H}_{0}: \mathrm{t}$ hitung $>\mathrm{t}$ table berarti ada pengaruh tingkat suku bunga deposito terhadap jumlah dana deposito berjangka 3 bulan.

2) $\mathrm{H}_{\mathrm{a}}: \mathrm{t}$ hitung $<\mathrm{t}$ table berarti tidak ada pengaruh tingkat suku bunga deposito terhadap jumlah dana deposito berjangka 3 bulan.

Nilai t table dilihat pada taraf signifikansi 0,05 , di mana $\mathrm{df}=$ (jumlah sampel - jumlah variable). Sehingga $\mathrm{df}$ $=(20-2)=18$ maka nilai t table adalah 1,734.

Berdasarkan table 3. diketahui nilai t hitung sebesar 0,056 sehingga nilai $\mathrm{t}$ hitung $0,056<\mathrm{t}$ table 1,734 maka dapat dikatakan bahwa secara parsial tidak terdapat pengaruh yang signifikan antara tingkat suku bunga deposito terhadap jumlah dana deposito berjangka 3 bulan pada PT. Bank Tabungan Pensiunan Nasional. Berarti hipotesis ditolak.

Hai ini dapat juga dibuktikan nilai signifikansi. Berdasarkan table 3. di atas diketahui nilai signifikansi tingkat suku bunga sebesar 0,956 > dari probabilitas 0,05 sehingga dapat disimpilkan bahwa tingkat suku bunga tidak berpegaruh terhadap jumlah dana deposito.

\section{Persamaan Regresi}

Dalam penelitian ini variabel $\mathrm{x}$ atau variabel independen yaitu tingkat suku bunga deposito berjangka sedangkan variabel $\mathrm{Y}$ atau variabel dependen yaitu yaitu jumlah dana deposito. Penelitian hanya melibatkan 1 variabel bebas (independen) maka disebut analisis regresi linier sederhana.

Persamaan regresi linier sederhana adalah :

$$
\mathrm{Y}=\mathrm{a}+\mathrm{bx}+\varepsilon \mathrm{i}
$$

Berdasarkan table 4. persamaan regresi sebagai berikut:

$$
\mathrm{Y}=14.607 .827,130+2.834 .222,996 \mathrm{x}
$$

Dimana $\mathrm{a}=14.607 .827,130$ artinya jika tidak ada pertambahan pada tingkat suku bunga deposito berjangka, maka jumlah deposito pada PT. Bank Tabungan Pensiunan Nasional akan mengalami penambahan sebesar Rp.14.607.827,130. Sedang nilai $b=2.834 .222,996$ artinya jika tingkat suku bunga deposito berjangka mengalami peningkatan sebesar $1 \%$, maka jumlah deposito pada PT. Bank Tabungan Pensiunan Nasional Tbk. akan mengalami peningkatan sebesar Rp.2.834.222,996.

\section{PEMBAHASAN}

Berdasarkan hasil penelitian di atas, menunjukkan bahwa tingkat suku bunga deposito $(\mathrm{X})$ tidak berpengaruh siginifikan terhadap jumlah dana deposito berjangka (Y) pada PT. Bank Tabungan Pesiunan Nasional Tbk. yang memiliki nilai t hitung sebesar 0,056 sehingga nilai t-hitung 0,056 lebih kecil dari nilai t-table 1,734 dan nilai signifikansi sebesar 0,956 yang lebih besar dari probabilitas 0,05. Hal ini mungkin karena nasabah deposito berjangka pada PT. BTPN Tbk. merupakan pensiunan sehingga dana yang ada, mereka simpan dalam bentuk deposito tanpa memperhatikan tingkat suku bunga.

Hasil penelitian ini sama dengan penelitian sebelumnya yang dilakukan oleh Natalie dan kawan-kawan (2014) dan Roby Jaya Putra (2018) pada Bank Umum Konvensional di Provinsi Aceh, yang menunjukkan bahwa tingkat suku bunga tidak berpengaruh signifikan terhadap jumlah dana deposito berjangka.

\section{KESIMPULAN}

Berdasarkan hasil analisis dan pembahasan yang telah dikemukakan di atas, maka penulis menarik kesimpulan sebagai berikut; tingkat suku bunga deposito (X) tidak berpengaruh siginifikan terhadap jumlah dana deposito berjangka (Y) pada PT. Bank Tabungan Pensiunan Nasional Tbk. Tingkat suku bunga deposito memiliki nilai t-hitung $0,056<$ dari nilai t-table 1,734 dengan nilai signifikansi sebesar $0,956>$ probabilitas 0,05 .

\section{SARAN}

Berdasarkan kesimpulan di atas, maka penulis mengemukakan saran sebagai berikut :

1. Hendaknya pihak bank mempromosikan keunggulan tingkat bunga dari bank lainnya. Dengan adanya promosi maka akan menarik calon nasabah lain karena tingkat bunga yang lebih tinggi akan meningkatkan jumlah dana deposito yang berarti tingkat kepercayaan deposan terhadap PT. BTPN juga semakin tinggi.

2. Bagi peneliti selanjutnya yang akan meneliti variabel yang sama, peneliti menyarankan untuk meneliti objek yang berbeda sehingga penelitian berikutnya dapat mendukung penelitian ini.

\section{DAFTAR PUSTAKA}

Ongki Wanadjati Dana, 2019, Analisis Pengaruh Tingkat suku Bunga Deposito Terhadap Jumlah Dana Deposito Berjangka Pada PT. Bank Tabungan Pensiunan Nasional.

Sugiyono, 2010, Metode Penelitian Kuantitatif Kualitatif dan R\&D; Penerbit. Cv Alfabeta Bandung.

Ikatan akuntasi Indonesia, 2014, Standar Akuntasi keuangan, salemba empat, Jakarta.

Sutojo, Siswanto (2000), Strategi Manajemen Kredit Bank Umum, Cetakan Kedua, Penerbit PT. Damar Mulia Pustaka, Jakarta. 
Sudjana (1991), Statistik Untuk Ekonomi dan Niaga, Edisi Baru, Penerbit Tarsito, Bandung.

Winarto Surachmad, 1997, Pengantar Penyelidikan Ilmiah Dasar dan Metodologi dan Metodologi Penelitian, Penerbit Erlangga,. Jakarta.

Munawir, 2014, Analisis Laporan Keuangan. Edisi empat penerbit, liberty Yogyakarta.

Novianto Aditiya, 2011, Analisis Pengaruh Nilai Tukar (Krus) Dolar Amerika/ Rupiah Tingkat suku Bunga SBI, Semarang.

Sunariyah, 2013, Pengantar pengetahuan pasar modal (edisi 6) Yogyakarta UPP. STIM. YKPN

Siswanto sutojo 2000, Strategi Manajemen Kredit Bank Umum. Cetakan Kedua, Penerbit PT. Damar Mulia Pustaka Jakarta.

Sugiyono, 2010, Metode Penelitian Kuantitatif Kualitatif dan R\&D; Penerbit. Cv Alfabeta Bandung.

www.btpn.com/doc/01012019/StrukturOrganisasi-

BTPN,2019 